\title{
Carbohydrate fermentation in the rumen-variations on a theme
}

\section{By J. D. SutTon, National Institute for Research in Dairying, Shinfield, Reading $R G 2 g A T$}

Fermentation in the rumen is by far the most important means whereby ruminants digest carbohydrates. For most diets the rumen accounts for over 0.9 of the digestion of all carbohydrates, although this value can be altered in certain circumstances. For instance, the proportion of fibre digestion occurring in the rumen may be considerably reduced when forages are ground and pelleted (Thomson, 1972) and, even more so, when free oils are added to the diet (Knight et al. 1978) and important differences in the site of starch digestion have been shown to exist among cereals (Sutton, 1976).

The major pathways of the fermentation and the nature of the products are well known although considerable debate still surrounds the key area of the disposal of metabolic hydrogen (Leng, 1973; Murray et al. 1978).

The extensive studies over the past 40 years of the role of carbohydrates in the energy transformations in the rumen have established a widely accepted picture of the quantitative aspects of the fermentation and the nature of the substrates and of the products. The over-all theme that has emerged is that about $0.60-0.75$ of apparently digested energy $\left(A D E_{T}\right)$ is apparently digested in the rumen $\left(A D E_{R}\right)$. It is generally assumed that: $A D E_{R}$ is approximately equivalent to the energy fermented (FE) to volatile fatty acids (VFA), heat and methane and removed from the rumen by passage, absorption or eructation (i.e. not re-incorporated into microbial organic matter) (Nicholson \& Sutton, 1969; Thomas \& Clapperton, 1972); carbohydrates are the principal substrate; the amounts of the main products can be calculated on stoichiometric principles and these indicate that $0.75-0.85$ of FE should be converted to VFA and the remainder lost as heat and methane; and the molar proportions of VFA found in the rumen reflect the proportions produced. Manipulation of the rumen fermentation is generally considered to offer a means of improving the efficiency of feed utilization.

The system is now considered to be sufficiently well understood for it to be included as a component of schemes now being introduced in several countries for predicting the protein requirements of ruminants. It is, therefore, timely to examine in more detail the complexities and uncertainties of some of the relationships that have tended to be obscured by the need to establish a simple set of factors for predictive purposes.

\section{Experimental observations of rumen balances}

The general theme described in the introduction is based on many different sources-in vivo, in vitro and theoretical. A survey of in vivo experiments indicates that the majority of results broadly agree with the theme (Leng, 1973), 
Table I. Estimates of the contribution of the energy of carbohydrate $(C-E)$ and crude protein $(P-E)^{*}$ to apparently digested energy in the rumen $\left(A D E_{R}\right)$ and of the energy of volatile fatty acids $(V F A-E)$ as a proportion of $A D E_{R}$ and of $C-E+P-E$ apparently digested in the rumen of sheep given forages.

Wheaten straw

Wheaten hay

Lucerne hay

Subterranean clover

Fresh silage

Formalin silage

Dried + formalin silage

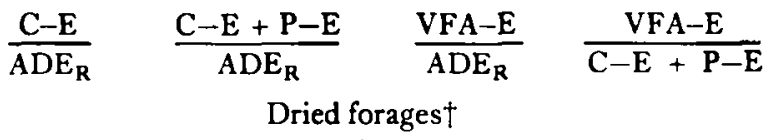

\begin{tabular}{|c|c|c|c|}
\hline \multicolumn{4}{|c|}{ Silages $\ddagger$} \\
\hline 0.51 & $0.5^{6}$ & 0.56 & 1.01 \\
\hline $\begin{array}{l}0.82 \\
0.86\end{array}$ & $\begin{array}{l}0.78 \\
0.82\end{array}$ & $\begin{array}{l}0.74 \\
0.74\end{array}$ & $\begin{array}{l}0.94 \\
0.90\end{array}$ \\
\hline
\end{tabular}

$\begin{array}{llll}0.91 & 0.81 & 0.58 & 0.72 \\ 0.59 & 0.58 & 0.50 & 0.86 \\ 0.62 & 0.66 & 0.64 & 0.97 \\ 0.63 & 0.68 & 0.55 & 0.81\end{array}$

-Based on the net change in total $\mathrm{N}$ between the food and duodenal flow.

†Calculated from Egan et al. (1975) and Walker et al. (1975).

$\ddagger$ Calculated from Beever et al. (1977).

but recently large variations have become apparent in some experiments.

Values derived from two experiments, both with sheep, are summarized in Table $\mathrm{I}$. In both experiments the apparent digestion of crude protein is based solely on the net change of total $\mathrm{N}$ between the food and duodenum and obviously involves a small error. The results of Egan et al. (1975) were published in terms of $g$ nutrients/ $d$ and have been converted to an energy basis. The important point is that in both experiments carbohydrates were estimated to account for less than two-thirds of $A D E_{R}$ for certain of the diets and correction for net changes in crude protein did little to alter this. The net result was that the substrate for $0.18-0.44$ of $\mathrm{ADE}_{\mathrm{R}}$ could not be identified. The energy of VFA production was considerably less than the value of $0.75-0.80$ of $\mathrm{ADE}_{\mathrm{R}}$ that would be expected on stoichiometric principles if $\mathrm{ADE}_{\mathrm{R}}$ were primarily due to carbohydrate fermentation. When expressed in relation to the energy of apparently digested carbohydrate and crude protein, better agreement with the theoretical value was obtained in the work of Egan et al. (1975) and Walker et al. (1975), but values were rather too high in the work of Beever et al. (1977).

The much lower values of VFA-E/ADE $\mathrm{R}_{\mathrm{R}}$ for fresh silage than for formalin silages in the work of Beever et al. (1977) almost exactly mirrored differences between frozen rye-grass and dried rye-grass found earlier by the same group (Beever et al. 1976). This strongly suggested that the discrepancy is less for forages that have been processed to reduce protein digestion in the rumen. However, in the studies of Walker et al. (1975), the reverse picture was obtained, VFA constituting a higher proportion of $\mathrm{ADOM}_{\mathrm{R}}$ when forages were fresh than when they were dried. 
The better agreement of VFA-E to apparently digested carbohydrate and protein than to $A D E_{R}$ suggests that, for most of the diets studied, $A D E_{R}$ was overestimating FE. Coupled with the failure to account for up to 0.44 of $A_{D E}$ in terms of carbohydrate and protein, these results could be interpreted as indicating the absorption from the rumen of an unfermented substrate that is not measured as carbohydrate or total $\mathrm{N}$. Such an explanation seems unlikely.

Unexpectedly low values for VFA-E/ADE ${ }_{R}$ are not confined to sheep. Although no attempts to measure VFA production and $A D E_{R}$ simultaneously in milking cows have been reported, comparison of the very few estimates of these two parameters when measured in separate experiments (see Sutton, 1976) indicates that VFA-E/ADE $\mathrm{R}_{\mathrm{R}}$ is only about 0.6 for milking cows fed twice daily. Simultaneous measurement of the two parameters in dry cows has yielded a slightly higher value of 0.66 (J. D. Sutton \& F. G. Youssef, unpublished results).

Although the experiments considered above share a common feature of unexpectedly low rates of production of VFA, it is important to emphasize the variable nature of deviations from the introductory theme. For instance, Murray et al. (1978) concluded that their estimates of VFA production were unexpectedly high and postulated that endogenous $O M$ is fermented in the rumen.

\section{Sources of errors}

Various reasons can be suggested for the disagreement between these results and the relationships summarized in the opening theme. They can be divided into two main groups.

Errors of measurement. (I) Measurement of the flow of digesta through the abomasum or duodenum are imprecise and may be inaccurate for a variety of reasons (Sutton \& Oldham, 1977).

(2) Methods used for the analysis of digesta have generally been developed for analysing feeds and may be quite unsuited to determining the mixture of microbial carbohydrates and partially degraded polysaccharides occurring in digesta.

(3) Measurement of VFA production presents many problems and its accuracy is often low. Use of $\mathrm{I}^{14} \mathrm{C}$-acetate to measure the production of all major VFA, as was done in most of the experiments considered, is particularly imprecise for diets containing readily fermentable carbohydrates though less so for dried forages (Sutton \& Morant, 1978). Further errors can arise from attempts to measure production in animals fed twice-daily and so not in steady state (Morant et al. 1978).

Errors of assumption. (I) The assumption that $A D E_{\mathrm{R}}$ represents $\mathrm{FE}$ involves a number of approximations (Czerkawski, 1978). The passage of up to $10 \%$ of rumen VFA to the duodenum and post-ruminal additions of OM from endogenous sources both cause $\mathrm{FE}$ to be slightly underestimated. A much greater underestimate, of the order of $0 \cdot 20-0 \cdot 25$, occurs when cannulas are sited beyond the point of entry of the bile and pancreatic ducts as in most published experiments with lactating cows (Sutton \& Oldham, 1977). Absorption of unfermented feed OM is normally negligible but could cause a considerable overestimate of FE when 
lipids such as coconut oil, rich in medium-chain fatty acids, are fed if the suggestion that such acids are absorbed directly from the stomach (Knight et al. 1977) is correct.

(2) The net production of VFA as measured by isotope dilution techniques is generally assumed to represent the VFA available for absorption. However, small amounts of the pool of VFA in the rumen fluid, probably about $2-3 \%$ of production, are incorporated into microbial $\mathrm{OM}$. It has recently been estimated that $14 \%$ of acetate production was catabolized to carbon dioxide in molasses-fed sheep (Rowe et al. 1979), but this is probably a special situation confined to diets causing very slow fluid turnover rates in the rumen.

(3) The difference between FE and the energy of VFA and methane production is generally assumed to represent heat of fermentation. Estimates of the true size of heat losses range widely according to the basis of the calculation and more reliable, in vivo values are needed.

It is clearly easier to identify the various sources of errors than to quantify them. With a few exceptions, most are probably quite small when taken in isolation but their combined effect, if generally biased in one direction, could be considerable.

\section{Rates of production of individual VFA}

The proportions of VFA in the rumen vary widely and are affected by many different factors, such as proportion of roughage, level of intake, frequency of feeding and type of cereal. A long-standing question is how closely the proportions of VFA occurring in the rumen reflect the proportions ultimately produced (net production) and available for absorption. Studies of the stoichiometry of rumen fermentation and of the energy metabolism of the host animal depend on a knowledge of this relationship.

It is now well-established that for high-forage diets the relationship is close, but recent experiments with sheep given widely different ratios of hay to concentrates (Sutton \& Morant, 1978) indicate that when diets contain a large proportion of concentrates, the relation between the proportions of VFA produced and the proportions present in the rumen is much more variable, though no consistent change in the relationship could be detected. It is still not clear whether the greater variability reflects physiological changes or merely technical problems. The dietary conditions that are likely to be associated with the greater variability also need closer definition. Until these problems are satisfactorily resolved, it must be accepted that the assumption that the proportions of VFA in the rumen reflect the proportions produced may involve considerable error for diets containing readily fermentable carbohydrates.

\section{Manipulation of rumen fermentation}

The pattern of fermentation naturally resulting from a particular dietary routine can be modified by additives that can act either directly on the feed (e.g. oils) or microbial population (e.g. antibiotics), or indirectly by influencing the rumen environment (e.g. $\mathrm{pH}$ or dilution rate) (Sutton, 1976). 
Certain general principles of manipulating rumen fermentation can be considered from an examination of the role of the dilution rate of rumen fluid in influencing rumen activity. The demonstration (Hodgson \& Thomas, 1975) that an inverse relationship existed in sheep between the dilution rate of rumen fluid and the molar proportion of propionic acid offered the possibility of manipulating the proportions of VFA if dilution rate could be altered. This possibility was realized by additions of salts by such means as intra-ruminal infusions (Harrison et al. 1975).

Two important points must be considered in relation to these observations. The first is the danger of extrapolating results and is illustrated in Fig. 1 . The large

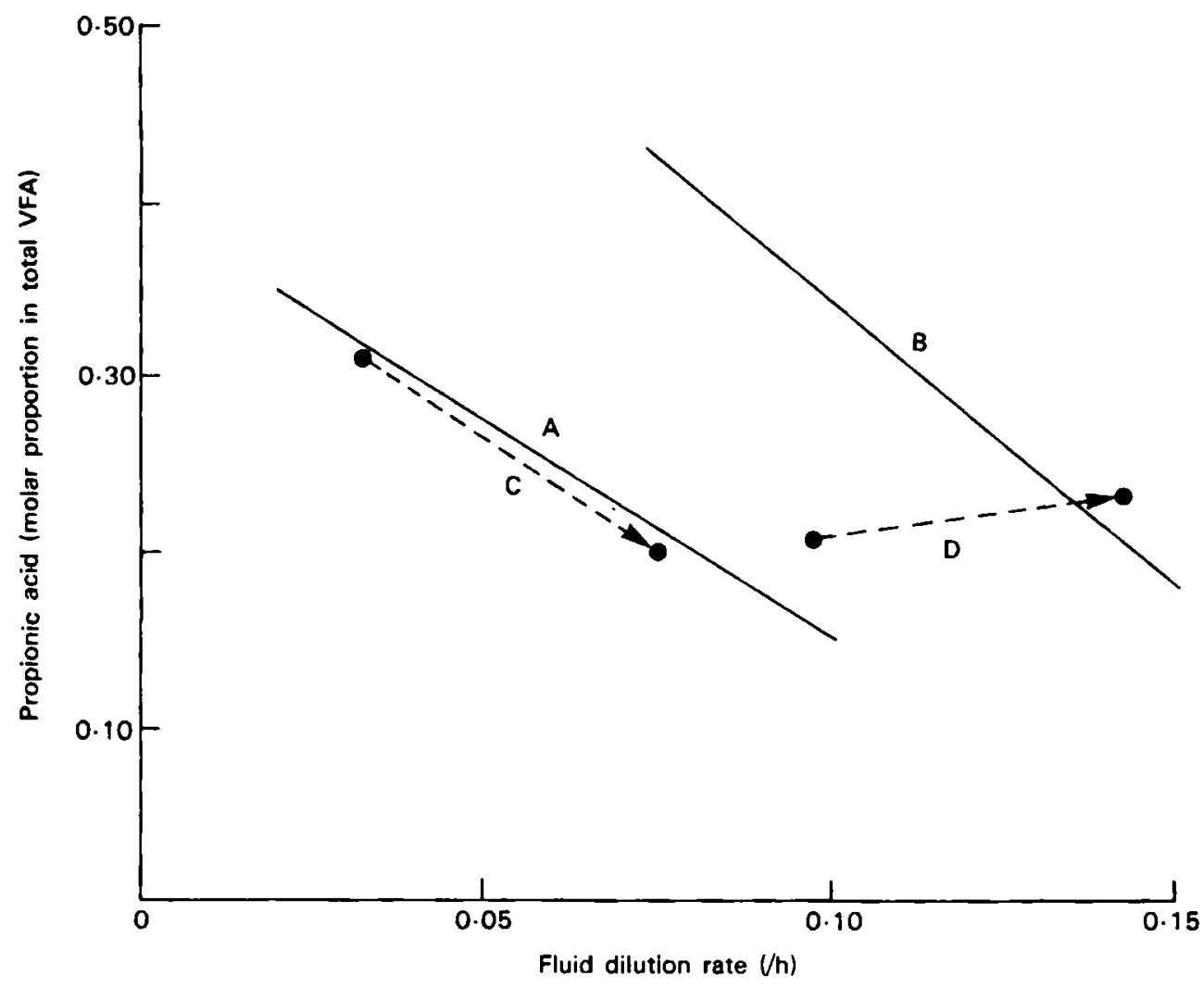

Fig. I. The relation between the molar proportions of propionic acid in the total volatile fatty acids and the dilution rate of rumen fluid in sheep ( $A$; Hodgson \& Thomas, 1975) and milking cows (B; J. D. Sutton \& J. D. Oldham, unpublished results) and the effect on the relationship in sheep of the intraruminal infusion of salts (C; Harrison et al. 1975) or of changing to a cold environment (D; Kennedy et al. 1976).

increase in dilution rate in the work by Kennedy et al. (1976) was achieved by moving sheep receiving a fixed diet from a normal to a cold environment but it did not significantly affect rumen VFA. With the milking cows given various diets of hay and concentrates (J. D. Sutton \& J. D. Oldham, unpublished results), propionic 
acid did fall as dilution rate fell, but the relationship is clearly different to that of Hodgson \& Thomas (r975). The second point is the close interrelationships of the whole rumen system, the result of which is that changes in one parameter are almost inevitably associated with other changes. For instance, increased dilution rates are accompanied by greater efficiency of microbial protein synthesis and a higher flow of starch from the rumen (Harrison et al. 1975); it seems probable that, associated with the reduction in propionic acid, methane production is increased but this does not appear to have been studied. Other additives such as free oils (Knight et al. 1978), monensin and methane inhibitors (Chalupa, 1977) have all been shown to affect several different aspects of rumen activity, including feed intake, the digestion of various feed constituents, VFA proportions, methane production and the efficiency of microbial protein synthesis.

Thus although it is possible, with varying degrees of success, to manipulate many aspects of the rumen fermentation, it is essential to consider the over-all effects of the manipulation on the whole rumen system. The disadvantages of the associated changes, such as reduced feed intake or rumen digestion, may outweigh the advantages expected from the primary purpose of the manipulation.

\section{Reliability of estimates of rumen digestion}

In the absence of absolute standards, assessment of the reliability of the various measurements of carbohydrate fermentation must be largely subjective. The more reliable appear to be $A D E_{R}$, methane production and VFA proportions. The less reliable are FE, heat losses, VFA production, absorption of unfermented $O M$ and carbohydrate analyses. Most of the measurements required to allow a satisfactory balance of carbohydrate fermentation to be calculated are included in the less reliable' group. It was because of the relatively high accuracy of methane measurements that Murray et al. (1978) suggested that, from a measurement of methane production, VFA production could be calculated on stoichiometric principles. It seems very doubtful whether present knowledge of the substrates and products of the fermentation of anything but the simplest diets is sufficiently precise for this to provide a satisfactory approach. Considerable efforts have been made in recent years to calculate the hydrogen balance within the rumen, but the variability of the results of many in vivo experiments suggest that the establishment of a satisfactory carbon balance should be given a greater priority.

How then are the conflicts between the in vivo results discussed earlier and the introductory theme to be evaluated? It is the opinion of the present author that the introductory theme is indeed broadly correct for most situations although $\mathrm{ADE}_{\mathrm{R}}$ probably slightly underestimates $\mathrm{FE}$ and unusual diets or additives may give rise to exceptions. This opinion leads inevitably to the further conclusion that the variations of the in vivo results from those suggested in the introductory theme reflect primarily technical problems. However, this opinion is based on little more than a balance of probabilities and a satisfactory solution of these problems will require the application of modelling, stoichiometry and improved techniques before a complete balance of carbohydrate fermentation can be achieved for many 
diets. Until then it must be concluded that present knowledge of carbohydrate fermentation in the rumen is sufficient to permit broad relationships to be described and manipulations monitored, but is inadequate for such purposes as modelling or metabolic studies.

\section{REFERENCES}

Beever, D. E., Thomson, D. J. \& Cammell, S. B. (1976). F. agric. Sci., Camb. 86, 443.

Beever, D. E., Thomson, D. J., Cammell, S. B. \& Harrison, D. G. (1977). J. agric. Sci., Camb. 88,61 .

Chalupa, W. (1977). f. Anim. Sci. 46, 585.

Czerkawski, J. W. (1978). J. Dairy Sci. 6r, r26r.

Egan, A. R., Walker, D. J., Nader, C. J. \& Storer, G. (1975). Aust. F. agric. Res. 26, 909.

Harrison, D. G., Beever, D. E., Thomson, D. J. \& Osbourn, D. F. (1975). F. Sci. Fd. Agric. 27, 617 .

Hodgson, J. C. \& Thomas, P. C. (1975). Br. F. Nutr. 33, 447.

Kennedy, P. M., Christopherson, R. J. \& Milligan, L. P. (1976). Br. F. Nutr. 36, 231.

Knight, R., Sutton, J. D., McAllan, A. B. \& Smith, R. H. (1978). Proc. Nutr. Soc. 37, 14A.

Knight, R., Sutton, J. D. \& Storry, J. E. (1977). Proc. Nutr. Soc. 36, 69 A.

Leng, R. A. (1973). In Chemistry and biochemistry of herbage, Vol. 3, p. 82. [G. W. Butler \& R. W. Bailey, editors]. London: Academic Press.

Morant, S. V., Ridley, J. L. \& Sutton, J. D. (1978). Br. F. Nutr. 39, 451.

Murray, R. M., Bryant, A. M. \& Leng, R. A. (1978). Br. F. Nutr. 39, 337

Nicholson, J. W. G. \& Sutton, J. D. (1969). Br. f. Nutr. 23, 585 .

Rowe, J. B., Loughnan, M. L., Nolan, J. V. \& Leng, R. A. (1979). Br. f. Nutr. 4r, 393.

Sutton, J. D. (1976). In Principles of cattle nutrition. p. I 2 I [H. Swan \& W. H. Broster, editors]. London: Butterworths.

Sutton, J. D. \& Morant, S. V. (1978). In Ruminant digestion and feed evaluation. p. 7.1. [D. F. Osbourn, D. E. Beever \& D. J. Thomson, editors]. London: Agricultural Research Council.

Sutton, J. D. \& Oldham, J. D. (1977). Proc. Nutr. Soc. 36, 203.

Thomas, P. C. \& Clapperton, J. L. (1972). Proc. Nutr. Soc. 31, 165.

Thomson, D. J. (1 972). Proc. Nutr. Soc. 3r, 127.

Walker, D. J., Egan, A. R., Nader, C. J., Ulyatt, M. J. \& Storer, G. B. (1975). Aust. F. agric. Res. 26, 699 . 